\title{
Evaluation of Cardiorespiratory Parameters Prior to Anatomical Lung Resection
}

\author{
Hamid Reza Mahoozi*, Gerasimos Varelis and Hamid Mofid
}

Section of Thoracic Surgery, Regio Kliniken, Pinneberg, Germany

\begin{abstract}
The evaluation of cardiopulmonary parameters is an essential factor for ascertaining of functional operability prior to anatomical lung resection. A predictive formulae for estimating of functional operability based on analysis of cardiorespiratory parameters have not yet been described. In marginal cases, a precise assessment is an important decisive factor under fear of postoperative complication regarding more radical parenchymal resection.

The functional tests such as spirometry, spiroergometry, stair climbing exercise, 6-Minute walk test, echocardiography, stress echocardiography and lung perfusion scintigram under consideration of general health situation could provide predictive postoperative information for ascertaining of functional operability.

We describe in this review the meaningful cardiorespiratory tests for estimating of the outcome prior to anatomical lung resection.
\end{abstract}

Keywords: Functional lung operability; Anatomical lung resection

Abbreviations: TIA: Transitory Ischemic Attack; BTS: British Thoracic Society; NSCLC: Non-Small-Cell Lung Carcinoma; PPO: Predicting Postoperative; FEV : Forced Expiratory Volume on First Second; DLCO: Diffusional Capacity for Carbon Monoxide; $\mathrm{VO}_{2} \max$ : Maximal Level of Oxygen Consumption; $\mathrm{VCO}_{2}$ : Maximal Level Carbon Dioxide Production; RCRI: Revised Cardiac Risk Index; THRCRI: Thoracic Revised Cardiac Risk Index; ESTS: European Society of Thoracic Surgeon; CRI: Cardiac Risk Index; ERS: European Respiratory Society

\section{Cardiorespiratory Functional Tests}

Testing patients to predict outcome prior to lung operation has been described since the history of surgery for lung tuberculosis [1]. After 70 years, we are still investigating for the best predictive factors and ideal test to predict precise outcome before our surgical procedure. A higher rate of survival could be provided for the selected patients with better evaluated cardiorespiratory parameters.

The first step to rectify our evaluation is Medical past history regarding of cardiovascular and respiratory diseases such as myocardial disease, myocardial infarct, cardiac interventions, cardiac arrhythmia, stroke, transitory ischemic attack (TIA) etc. as well as COPD history and related medications, another respiratory diseases. Comorbidities and physical activity should be noticed and evaluated.

\section{Age}

According to S3 German guideline; age is not an excluding criteria for curative surgical resection. The BTS (British Thoracic Society) advices, age over 80 alone is not a contraindication to lobectomy or wedge resection for clinically stage I disease [Level B] [2]. There is growing evidence from recent studies, which confirms relative safety of lung resection in the elderly patients [3]. Age by itself should not be an excluding factor for curative surgical resection in early stage of NonSmall-Cell Lung Carcinoma (NSCLC) [3].

Nowadays there are the following applicable tests for estimating of functional operability.

\section{Spirometry}

The spirometry is in the first line for prediction of postoperative risks in our daily practice. The lung function test including forced expiratory volume in first second $\left(\mathrm{FEV}_{1}\right)$ and diffusional capacity for carbon monoxide (DLCO) as well as calculating of predicting postoperative forced expiratory volume in first second $\left(\mathrm{ppoFEV}_{1}\right)$ and predicting postoperative diffusional capacity for carbon monoxide (ppoDLCO) are the necessary respiratory parameters prior to anatomical lung resection. According to BTS (British Thoracic Society) guidelines, no further respiratory function tests are required for a lobectomy if the post-bronchodilator $\mathrm{FEV}_{1}$ is $>1.5 \mathrm{~L}$ and for a pneumonectomy if the post-bronchodilator $\mathrm{FEV}_{1}$ is $>2.0 \mathrm{~L}$ [Level B] [4].

For the patients with borderline operability (ppo $\mathrm{FEV}_{1}$ between 0.8-1.5 L or DLCO between 40-50\%) based on spirometry should be performed further tests such as estimation of transfer factor (DLCO) and predicting postoperative diffusional capacity for carbon monoxide (ppoDLCO), Spiroergometry and measurement of $\mathrm{VO}_{2}$ max, using the lung perfusion scan with anatomical equation percentage.

\section{Spiroergometry}

Spiroergometry provide more precise meaningful finding out compared with spirometry with simultaneous measuring of oxygen $(\mathrm{O} 2)$, carbon dioxide $\left(\mathrm{CO}_{2}\right)$, determining of the maximal level of oxygen consumption $\left(\mathrm{VO}_{2} \mathrm{max}\right)$ and carbon dioxide production $\left(\mathrm{VCO}_{2}\right)$ in the air the patient is breathing. At same time, the another parameters such as respiratory volumes and measure of Continuously heart rate with exercise ECG as well as blood pressure values are registered. Maximal level of oxygen consumption $\left(\mathrm{VO}_{2}\right.$ max) provides assessment of aerobic muscle groups and estimating of functional reserve. Bechard et al reported a high rate $(29 \%)$ of mortality in patients with $\mathrm{VO}_{2}$ max less than $10 \mathrm{ml} / \mathrm{kg} / \mathrm{min}[5]$.

The interdisciplinary guideline of the German Respiratory Society

*Corresponding author: Hamid Reza Mahoozi, Section of Thoracic Surgery, Regio Kliniken, Pinneberg, Germany, Tel: 4941012178664; E-mail: info@drmahoozi.com

Received December 13, 2017; Accepted December 20, 2017; Published December 26, 2017

Citation: Mahoozi HR, Varelis G, Mofid H (2017) Evaluation of Cardiorespiratory Parameters Prior to Anatomical Lung Resection. J Pulm Respir Med 7: 439. doi 10.4172/2161-105X.1000439

Copyright: (c) 2017 Mahoozi HR, et al. This is an open-access article distributed under the terms of the Creative Commons Attribution License, which permits unrestricted use, distribution, and reproduction in any medium, provided the original author and source are credited. 
and the German Cancer Society suggests performing of Spiroergometry for patients with ppoFEV 1 between $800 \mathrm{ml}$ to $2 \mathrm{Ls}$ and ppoDLCO between $30-60 \%$. The patients with predicted $\mathrm{VO}_{2} \max >75 \%$ or $\mathrm{VO}_{2}$ $\max >20 \mathrm{ml} / \mathrm{min} / \mathrm{kg}$ are considered as operable up to pneumonectomy. The patients with $\mathrm{VO}_{2} \max <35 \%$ or $\mathrm{VO}_{2} \max <10 \mathrm{ml} / \mathrm{min} / \mathrm{kg}$ should be considered as inoperable. The patients with $\mathrm{ppoVO}_{2} \max >35 \%$ or ppoVO $\max >10 \mathrm{ml} / \mathrm{min} / \mathrm{kg}$ are operable up to calculated size (Figure 1) $[6]$.

Sometime many patients don't achieve the maximal threshold of incremental exercise testing. In this cases, the another exercise testing such as 6-Minute walk test and stair climb could provide more informations about prediction of postoperative complication.

\section{6-Minute Walk Test}

The 6-Minutes. Walk test is performing twice in the same day. The patient is instructed to walk in a hall with measuring the oxygen saturation and heart rate with an interval for 5 minutes between both walk tests. Holden et al has been shown 6 minutes walk distance of $304 \mathrm{~m}$ or 1000 feet should be as threshold value for determine surgical morbidity and mortality [7]. The results of another studies regarding 12

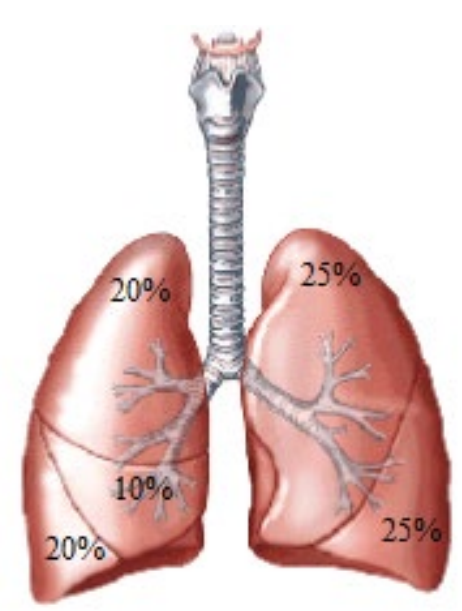

Figure 1: the percentage of planned resected area should be deducted from measured $\mathrm{VO}_{2}$ max. For example for left upper lobectomy, 25\% should be deducted from $\mathrm{VO}_{2}$ max.

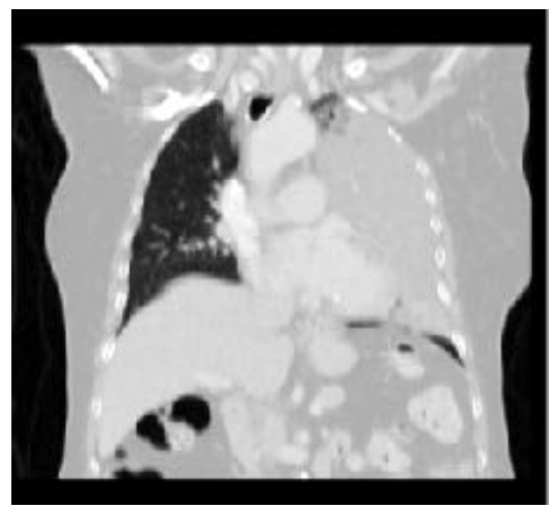

Figure 2: $\mathrm{VO}_{2} \max 12 \mathrm{ml} / \mathrm{min} / \mathrm{kg}$, lung perfusion scintigraphy li. $5 \%$, re. $95 \%$. Functional reserve after pneumonectomy is almost intact. minutes. Walk test were variable. The 12 minutes. Walk test does not correlate well with $\mathrm{FEV}_{1}$ [8].

\section{Stair Climb Test}

Stair climb test is a simple and familiar exercise test without difficulty for understanding the instructions to predict of functional operability. Every flight with 11 steps is counted as a unit of exercise. The cardiorespiratory parameters (oxygen saturation and heart rate) should be registered at the top of every flight. Holden et al demonstrated patients perform more work during stair climb than 6 minutes. Walk test as well as a stair climb of 44 steps should be recognised as a threshold value for estimating of functional operability [7]. In this study was stair climb more reliable than 6 minutes. Walk test for predicting of functional operability [7].

\section{Lung Perfusion Scintigraphy}

Lung perfusion scintigraphy is sometime employed in borderline cases for prediction of functional operability. The role of scintigraphy should be interpreted in relation of calculated size of parenchymal resection in preoperative CT Thorax and spiroergometry. The percentage of calculated size is deducted from $\mathrm{VO}_{2}$ max. According to BTS guideline as well as interdisciplinary guideline of the German Respiratory Society and the German Cancer Society, the patients with $\mathrm{ppoVO}_{2} \max >35 \%$ or $\mathrm{ppoVO}_{2} \max >10 \mathrm{ml} / \mathrm{min} / \mathrm{kg}$ are operable up to calculated size [6]. Lung perfusion scintigraphy is always helpful prior to pneumonectomy. For example a pneumonectomy left in a patient with a Lung perfusion scintigraphy of $5 \%$ in the left side concludes about $5 \%$ loss of functional reserve. In this case a $\mathrm{VO}_{2}$ max of $12 \mathrm{ml} /$ $\mathrm{min} / \mathrm{kg}$ results a ppoVO $\max 11.4 \mathrm{ml} / \mathrm{min} / \mathrm{kg}$. Because of functional pneumonectomy (left lung without function) in this case, the patient loses about $0.6 \mathrm{ml} / \mathrm{min} / \mathrm{kg}$ of his functional reserve. Therefore the functional omitted part should be considered in our Evaluation for functional operability (Figure 2).

\section{Cardial Parameters}

Some algorithms such as Revised Cardiac Risk Index (RCRI) and Thoracic Revised Cardiac Risk Index (THRCRI) were elaborated the predicted risk factors prior to major lung resection.

\begin{tabular}{|l|}
\multicolumn{1}{|c|}{ Revised cardiac risk index } \\
\hline 1. History of ischemic heart disease \\
\hline 2. History of congestive heart failure \\
\hline 3. History of cerebrovascular disease (stroke or transient ischemic attack) \\
\hline 4. History of diabetes requiring preoperative insulin use \\
\hline 5. Chronic kidney disease (creatinine $>2 \mathrm{mg} / \mathrm{dL}$ ) \\
\hline 6. Undergoing suprainguinal vascular, intraperitoneal, or intrathoracic surgery \\
\hline $\begin{array}{l}\text { Risk for cardiac death, nonfatal myocardial infarction, and nonfatal cardiac } \\
\text { arrest: } 0 \text { predictors }=0.4 \%, 1 \text { predictor }=0.9 \%, 2 \text { predictors }=6.6 \%, \geq 3 \text { predictors }=> \\
11 \%[8] .\end{array}$ \\
\hline
\end{tabular}

Table 1: Revised cardiac risk index.

Thorax revised cardiac risk index

1. History of ischemic heart disease

2. History of cerebrovascular disease

3. Serum creatinine level greater than $2 \mathrm{mg} / \mathrm{dL}$

4. Pneumonectomy

Ischemic heart disease (score=1.5 points), history of cerebrovascular disease (score $=1.5$ points), Creatinine level $>2 \mathrm{mg} / \mathrm{dL}$ (score=1 point), pneumonectomy (score=1.5 points)

Table 2: Thorax revised cardiac risk index. 
Goldman et al has developed in 1977 the first cardiac risk index (CRI) with nine variables, which were associated with increased postoperative cardiac complications [9]. Lee et al. defined in 1999 the modified cardiac risk factors as the revised cardiac risk index (RCRI) with six independents parameters as the predicted factors of increased preoperative cardiac complications. A modified form of revised cardiac risk index (RCRI) was published as guideline for prediction of preoperative cardiac complications from the American Heart Association and American College of Cardiology [10]. According to ESTS guideline, the patients with a score greater than 1 should be counselled for increased risk of major cardiac complication (Table 1).

The ThRCRI is included four individual components (1) Ischemic heart disease: The presence of history of myocardial infarction, history of a positive exercise test, current complaint of chest pain considered to be related to myocardial ischemia, use of nitrate therapy, or electrocardiogram with pathologic $\mathrm{Q}$ waves (score $=1.5$ points); (2) History of cerebrovascular disease: transient ischemic attack or stroke (score $=1.5$ points); (3) Serum creatinine level greater than 2 $\mathrm{mg} / \mathrm{dL}$ (score=1 point); and (4) Pneumonectomy (score=1.5 points) [11]. This components are known to be related with increased risk of preoperative mortality. The patients are classified in class A (score, 0 to 1 ), class B (score, 1.5 to 2.5 ) and class C (score $>2.5$ ). Some studies have been shown the THRCRI as a useful prognostic score system for risk stratification prior to resection for early-stage lung cancer [1214]. According to THRCRI score system, a score greater than 2.5 is associated with increased risk of major preoperative cardiac events (Table 2).

\section{Discussion and Conclusion}

According to recommendations of published guidelines by European Society of Thoracic Surgeons (ESTS) and European Respiratory Society (ERS), all patients with ppoFEV $<<80 \%$ and ppoTLCO $<80 \%$ should be evaluated precisely for functional operability through exercise tests. Sometimes one exercise test is not enough convincing to estimate the risk of postoperative complications, another exercise tests should be performed. In most of cases spiroergomety and stair climbing give you convincing information's to estimate the functional operability. THRCRI Score should be measured for all patients prior to major lung resections and the patients with a score greater than 2.5 should be considered as high risk for major cardiac events and a cardiac counseling is necessary.

\section{References}

1. Gaensler EA, Cugell DW, Lindgren I, Verstraeten JM, Smith SS, et al. (1955) The role of pulmonary insufficiency in mortality and invalidism following surgery for pulmonary tuberculosis. J Thorac Cardiovasc Surg 29: 163-187.

2. Klionsky DJ, Abdelmohsen K, Abe A, Abedin MJ, Abeliovich H, et al. (2012) Guidelines for the use and interpretation of assays for monitoring autophagy ( $3^{\text {rd }}$ edition). Autophagy 8: 445-544.

3. British Thoracic Society (2001) Society of cardiothoracic surgeons of great britain and ireland working party. Guidelines on the selection of patients with lung cancer for surgery. Thorax 56: 89-108.

4. Bechard D, Wetstein $L$ (1987) Assessment of exercise oxygen consumption as preoperative criterion for lung resection. Ann Thorac Surg 44: 344-349.

5. Goeckenjan G, Sitter H, Thomas M, Branscheid D (2011) Prevention, diagnosis, therapy, and follow-up of lung cancer. Pneumologie: 64 suppl: e1-e164.

6. Holden DA, Rice TW, Stelmach K, Meeker DP (1992) Exercise testing, 6-min walk, and stair climb in the evaluation of patients at high risk for pulmonary resection. Chest 102: 1774-1779.

7. Mc Gavin CR, Gupta SP, McHardy GJR (1976) Twelve minute walking test for assessing disability in chronic bronchitis. Br Med J 1: 822-823.

8. Goldman L, Caldera D L, Nussbaum SR, Southwick FS, Krogstad D et al. (1977) Multifactorial index of cardiac risk in noncardiac surgical procedures. New Eng J Med 297: 845-850.

9. Fleisher LA, Beckman JA, Brown KA, Calkins H, Chaikof E, et al. (2007) ACC AHA 2007 guidelines on perioperative cardiovascular evaluation and care for noncardiac surgery: executive summary. J Am Coll Cardiol 50: 1707-1732.

10. Kim DJ, Lee JG, Lee CY, Park IK, Chung KY (2007) Long-term survival following pneumonectomy for non-small cell lung cancer: Clinical implications for follow-up care. Chest 132: 178-184.

11. Thomas DC, Blasberg JD, Arnold BN, Rosen JE, Salazar MC, et al. (2017) Validating the thoracic revised cardiac risk index following lung resection. Ann Thorac Surg 104: 389-394.

12. Brunelli A, Ferguson MK, Salati M, Vigneswaran WT, Jimenez MF, et al. (2015) Thoracic revised cardiac risk index is associated with prognosis after resection for stage 1 lung cancer. Ann Thorac Surg 100: 195-200.

13. Rodríguez M, Gómez MT, Jiménez MF, Aranda JL, Novoa N, et al. (2013) The risk of death due to cardiorespiratory causes increases with time after right pneumonectomy: A propensity score-matched analysis. Eur J Cardiothorac Surg 44: 93-97.

14. Kim DJ, Lee JG, Lee CY, Park IK, Chung KY (2007) Long-term survival following pneumonectomy for non-small cell lung cancer: clinical implications for follow-up care. Chest 132: 178-184. 